\title{
Correlation of morphologic and pathologic features of the various tendon groups around the ankle: MR imaging investigation
}

\author{
Pedro Cabral • Cláudia Paulino • Rogério Takahashi • \\ Paul Clopton • Donald Resnick
}

Received: 22 January 2013 /Revised: 5 May 2013 /Accepted: 6 May 2013 / Published online: 3 July 2013

(C) The Author(s) 2013. This article is published with open access at Springerlink.com

\begin{abstract}
Objective To determine if a statistical association exists between abnormalities in one ankle tendon group (i.e., peroneal, medial flexor, or Achilles) and those in another. Materials and methods A retrospective analysis of 1.5-T and 3-T MR ankle examinations in 100 patients conducted between November 1, 2011 and April 1, 2012 was performed. The cross-sectional areas and diameters of the ankle tendons-Achilles (ACH), peroneus brevis ( $\mathrm{PB})$ and longus $(\mathrm{PL})$, tibialis posterior (TP), flexor digitorum longus (FDL), and flexor hallux longus (FHL) - were measured, and the results were correlated to determine any association with the presence of qualitative abnormalities (tenosynovitis, tendinosis, and tendon tearing).

Results Subjects with larger diameters of the ACH tendon also revealed larger PL, TP, FDL, and FHL tendon
\end{abstract}

P. Cabral $(\bowtie)$

Department of Radiology, Prof. Doutor Fernando Fonseca Hospital,

IC 19 - Venteira, 2720-276 Amadora, Portugal

e-mail: pvaldezpt@yahoo.com

C. Paulino

Department of Radiology, Coimbra University Hospital, Praceta Mota Pinto, 3000-075 Coimbra, Portugal

R. Takahashi

Centro de Diagnósticos Brasil,

Rua Diogo de Faria, 470/490 - Vila Clementino,

São Paulo, SP, Brazil 04037001

P. Clopton

Research \& Development Service,

Veterans Affairs San Diego Healthcare System,

3350 La Jolla Village Drive, San Diego, CA 92161, USA

D. Resnick

UCSD Teleradiology Center, 8899 University Center Lane,

Suite 370, San Diego, CA 92122, USA diameters and sectional areas. Furthermore, subjects with larger PL tendons generally revealed larger flexor tendons and the same was also true when medial compartment tendons were individually assessed and measurements compared among the three of them. There was a statistically significant association with regard to the presence of tendon abnormalities (tendinosis, tenosynovitis, and tearing) in both the peroneal and medial flexor tendons. The presence of an abnormality in the ACH tendon correlated strongly with increasing diameters and areas of all the other ankle tendons except for the PB tendon.

Conclusions There is an association between quantitative and qualitative abnormalities of one group of tendons when compared with the others with respect to the $\mathrm{ACH}$, medial flexor, and peroneal tendons of the ankle, which is perhaps explained by a retinacular and fascial complex that anatomically connects the three groups.

Keywords Ankle $\cdot$ Tendons $\cdot$ Magnetic resonance imaging

\section{Introduction}

Gross cadaveric studies have confirmed a complex interconnected system of retaining fascia and retinacula in the distal aspect of the leg, just above and at the level of the ankle, that create distinct tendon compartments $[1,2]$. Furthermore, recent evidence has shown that these and other retinacula also play a functional role, as they are not simply static structures for joint stabilization, like ligaments, but rather provide local spatial proprioception during movements of the foot and ankle [3]. One well-described example of this anatomic interconnected system is the continuity of the superior peroneal retinaculum and the flexor retinaculum of the ankle with the superficial and deep layers of the crural 


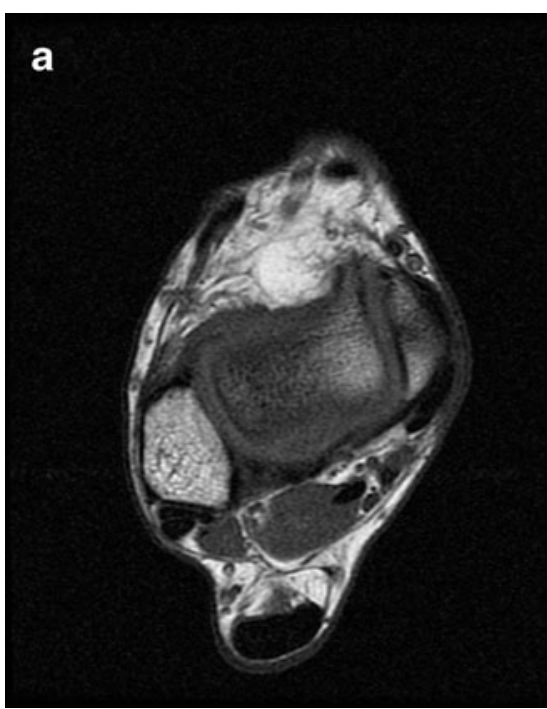

Fig. 1 Axial T1-weighted MR image depicting the retinacula and the tendons at the ankle. The tendons are painted: the Achilles is green, the peroneus longus is red, the peroneus brevis is orange, the tibialis posterior is dark blue, the flexor digitorum longus is light blue and the flexor hallux longus is purple. The yellow line corresponds to the

fascia, together forming a basket-shaped structure around the Achilles $(\mathrm{ACH})$ tendon in the region of the pre-Achilles fat pad (Fig. 1).

Owing to the presence of this system, myofascial pathology, even if located far from the ankle, may produce traction on the

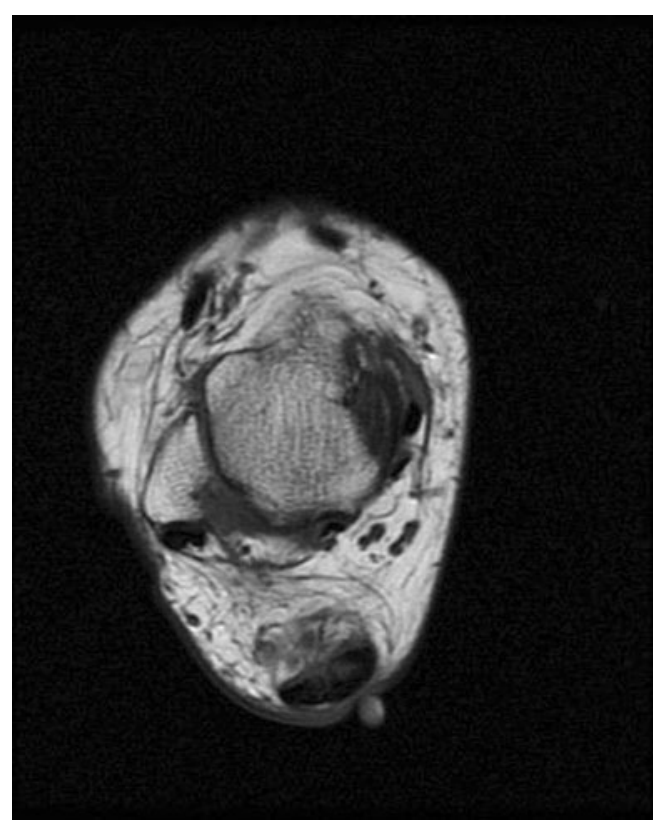

Fig. 2 Axial T1-weighted MR image $15 \mathrm{~mm}$ above the fibular tip, where the peroneal tendons were measured. Notice the association between partial Achilles tendon rupture and flexor hallux longus tenosynovitis

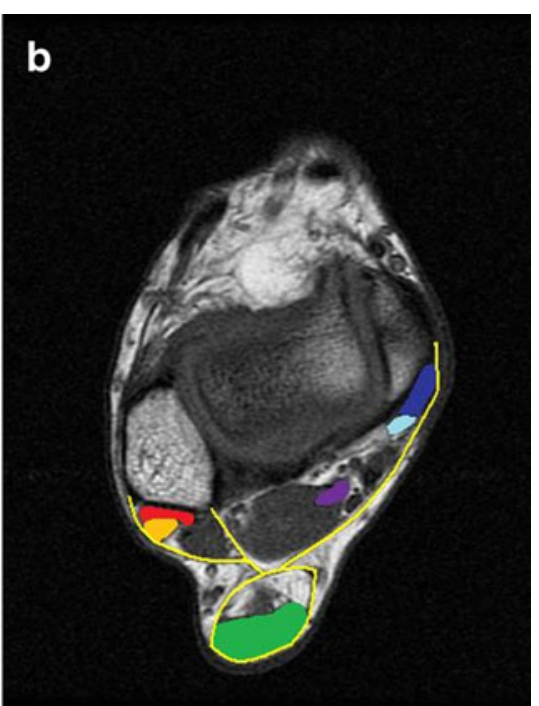

retinacula. It is subdivided in the superior peroneal retinaculum attaching laterally to the lateral malleolus and medially in continuity with the superficial and deep aponeuroses of the posterior compartment of the lower portion of the leg. The segment of retinacula around the flexor tendons is called the flexor retinaculum

retinacula at the level of the ankle and eventually predisposing to tendon, ligament, or even articular abnormalities [4].

A link between $\mathrm{ACH}$ tendon disorders and abnormalities of the surrounding retinacula has been emphasized, we

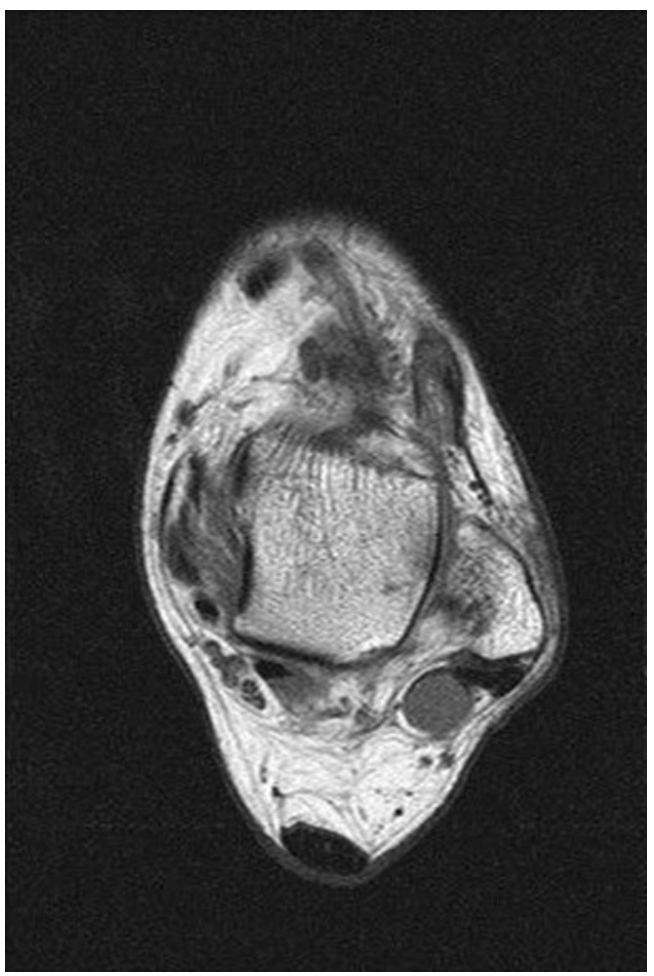

Fig. 3 Axial T1-weighted MR image $6 \mathrm{~mm}$ below the level of the talar dome, where the flexor tendons were measured 
Table 1 Mean, 10th, 50th, and 90th percentiles, range and standard deviation for diameters and area of ankle tendons $(\mathrm{cm})$

\begin{tabular}{|c|c|c|c|c|c|c|c|}
\hline Tendons & Diameter/area & Mean & $\begin{array}{l}\text { 10th } \\
\text { percentile }\end{array}$ & $\begin{array}{l}\text { 50th percentile } \\
\text { (median) }\end{array}$ & $\begin{array}{l}\text { 90th } \\
\text { percentile }\end{array}$ & Range & $\begin{array}{l}\text { Standard } \\
\text { deviation }\end{array}$ \\
\hline \multirow[t]{2}{*}{ Achilles } & Transverse & 1.421 & 1.129 & 1.365 & 1.764 & $0.930-2.320$ & 0.282 \\
\hline & Anteroposterior & 0.726 & 0.549 & 0.670 & 1.041 & $0.450-1.480$ & 0.214 \\
\hline \multirow[t]{3}{*}{ Peroneus longus } & Transverse & 0.672 & 0.500 & 0.670 & 0.860 & $0.280-1.010$ & 0.139 \\
\hline & Anteroposterior & 0.412 & 0.259 & 0.410 & 0.561 & $0.170-0.790$ & 0.115 \\
\hline & Area & 0.216 & 0.124 & 0.214 & 0.306 & $0.069-0.446$ & 0.072 \\
\hline \multirow[t]{3}{*}{ Peroneus brevis } & Transverse & 0.645 & 0.339 & 0.605 & 0.970 & $0.170-1.380$ & 0.246 \\
\hline & Anteroposterior & 0.298 & 0.139 & 0.250 & 0.500 & $0.080-1.060$ & 0.171 \\
\hline & Area & 0.143 & 0.063 & 0.118 & 0.281 & $0.034-0.699$ & 0.098 \\
\hline \multirow[t]{3}{*}{ Tibialis posterior } & Transverse & 0.485 & 0.330 & 0.480 & 0.632 & $0.210-0.890$ & 0.130 \\
\hline & Anteroposterior & 1.042 & 0.799 & 1.040 & 1.300 & $0.440-1.590$ & 0.208 \\
\hline & Area & 0.397 & 0.229 & 0.371 & 0.579 & $0.137-0.874$ & 0.134 \\
\hline \multirow{3}{*}{$\begin{array}{l}\text { Flexor digitorum } \\
\text { longus }\end{array}$} & Transverse & 0.490 & 0.329 & 0.470 & 0.662 & $0.190-0.930$ & 0.133 \\
\hline & Anteroposterior & 0.398 & 0.250 & 0.380 & 0.551 & $0.190-0.800$ & 0.122 \\
\hline & Area & 0.152 & 0.088 & 0.140 & 0.221 & $0.048-0.436$ & 0.060 \\
\hline \multirow[t]{3}{*}{ Flexor hallux longus } & Transverse & 0.541 & 0.400 & 0.510 & 0.710 & $0.990-0.250$ & 0.130 \\
\hline & Anteroposterior & 0.381 & 0.259 & 0.380 & 0.482 & $0.620-0.190$ & 0.090 \\
\hline & Area & 0.165 & 0.092 & 0.152 & 0.237 & $0.043-0.463$ & 0.065 \\
\hline
\end{tabular}

believe, only twice in the literature $[5,6]$. Although abnormalities of the $\mathrm{ACH}$, peroneal, and medial flexor tendons of the ankle have been widely studied, these tendon groups have always been regarded as independent structures, and a possible anatomical and functional association of pathology in these groups has largely been ignored [7-13].

Anecdotal evidence in our clinical practice appears to show an association of $\mathrm{ACH}$ tendon abnormalities with similar abnormalities of other ankle tendons, particularly

Table 2 Relationship between the dimensions of the Achilles tendon and the other ankle tendons

\begin{tabular}{|c|c|c|c|c|c|}
\hline \multirow[t]{2}{*}{ Tendons } & \multirow[t]{2}{*}{ Diameter/area } & \multicolumn{2}{|c|}{ Achilles tendon transverse diameter } & \multicolumn{2}{|c|}{ Achilles tendon anteroposterior diameter } \\
\hline & & $p$ value $^{\mathrm{a}}$ & $r$ value $^{\mathrm{b}}$ & $p$ value $^{\mathrm{a}}$ & $r$ value ${ }^{\mathrm{b}}$ \\
\hline \multirow[t]{3}{*}{ Peroneus longus } & Transverse & $<0.001$ & 0.345 & 0.035 & 0.212 \\
\hline & Anteroposterior & 0.073 & 0.18 & 0.027 & 0.222 \\
\hline & Area & $<0.001$ & 0.393 & $<0.001$ & 0.368 \\
\hline \multirow[t]{3}{*}{ Peroneus brevis } & Transverse & 0.061 & 0.188 & 0.260 & 0.114 \\
\hline & Anteroposterior & 0.367 & -0.910 & 0.937 & -0.008 \\
\hline & Area & 0.905 & -0.012 & 0.677 & 0.042 \\
\hline \multirow[t]{3}{*}{ Tibialis posterior } & Transverse & 0.457 & 0.075 & 0.100 & 0.165 \\
\hline & Anteroposterior & 0.007 & 0.266 & 0.027 & 0.221 \\
\hline & Area & 0.014 & 0.244 & 0.004 & 0.287 \\
\hline \multirow[t]{3}{*}{ Flexor digitorum longus } & Transverse & 0.001 & 0.335 & 0.001 & 0.326 \\
\hline & Anteroposterior & 0.518 & 0.065 & 0.171 & 0.138 \\
\hline & Area & 0.003 & 0.295 & $<0.001$ & 0.355 \\
\hline \multirow[t]{3}{*}{ Flexor hallux longus } & Transverse & $<0.001$ & 0.400 & 0.018 & 0.237 \\
\hline & Anteroposterior & 0.005 & 0.276 & $<0.001$ & 0.368 \\
\hline & Area & $<0.001$ & 0.415 & $<0.001$ & 0.347 \\
\hline
\end{tabular}

${ }^{\text {a }}$ Calculated with ANOVA test

${ }^{\mathrm{b}}$ Calculated with Pearson correlation test 


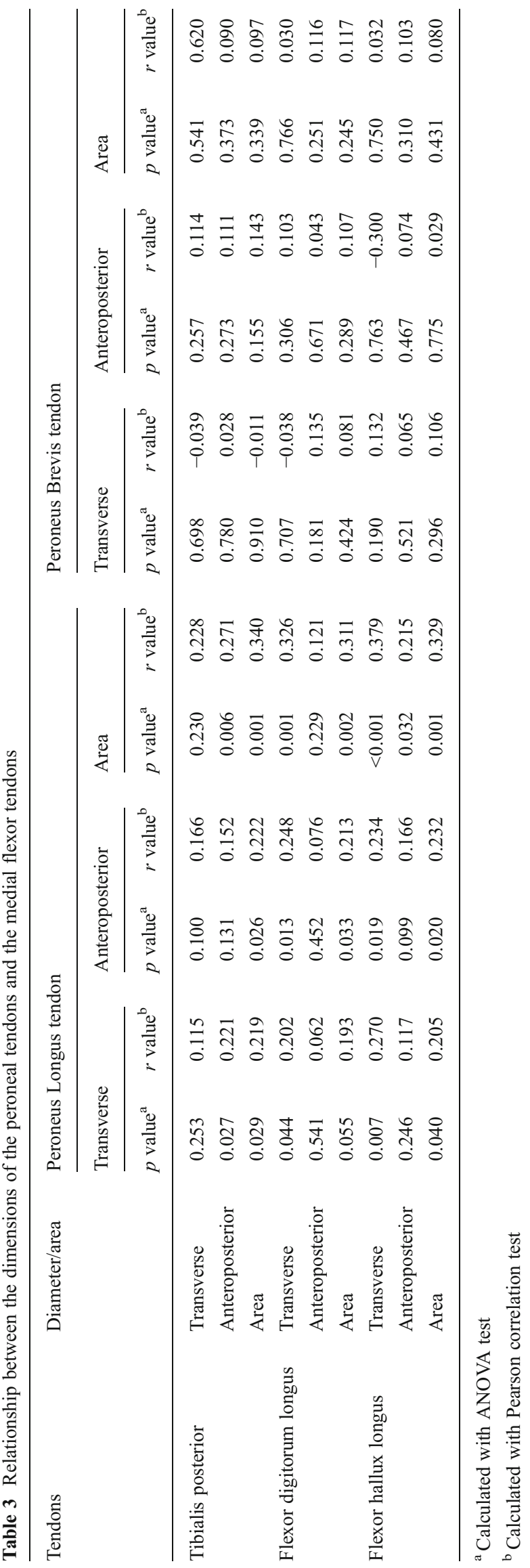

the peroneus longus (PL) and brevis (PB) tendons. Our hypothesis is that abnormalities of the ACH tendon, which is centrally located in this retention system of fascia and retinacula, may predispose to abnormalities in neighboring tendons. In short, this study was initiated to search for an association between $\mathrm{ACH}$, peroneal, and medial flexor tendons abnormalities.

\section{Materials and methods}

Patient selection

Institutional ethics review board approval was obtained. Between November 1, 2011, and April 1, 2012, 100 MR imaging studies of the ankle from 100 consecutive different patients were selected from our institution's database and were retrospectively examined. Exclusion criteria were bone fracture, previous surgery, severe osteoarthritis, rheumatoid arthritis or other inflammatory arthritides, diabetes mellitus, end-stage chronic renal disease, gout, dyslipidemia, infection, developmental abnormalities of the foot and ankle, or a history of systemic corticosteroid therapy.

Data were gathered from 100 consecutive patients (54 right ankles and 46 left ankles) of which 52 were women and 48 were men, with a mean age at time of imaging of 48 years (range, $17-92$ years) and a mean weight of $79 \mathrm{~kg}$ (range, $50.80-136.08 \mathrm{~kg}$ ).

Image protocol

MR images were obtained with four 1.5-T units (Siemens Symphony, GE Twinspeed Excite System, and two GE Signa Echospeed HDX) and a 3.0-T unit (GE Twinspeed). All studies included sequences in the axial, coronal, and sagittal planes with $\mathrm{T} 1$ and $\mathrm{T} 2$ fat-saturated or PD-weighted image acquisition, a section thickness of $2.5 \mathrm{~mm}$ with $0.5 \mathrm{~mm}$ interspace thickness, field of view $12 \times 12 \mathrm{~cm}$ and matrix size $512 \times 256$. A knee coil was centered just anterior to the tibiotalar joint.

In order to try to define the degree of ankle flexion or extension during imaging, an angle was defined according to that described in previous reports based only on conventional radiography. The angle was measured between the long axis of the tibia and the longest anteroposterior diameter of the talus. Unfortunately, these angle measurements have not yet been validated for MR imaging in large controlled trials $[1$, 14]. In our group, the mean angle was $85^{\circ}$ (range, $67^{\circ}-101^{\circ}$ ).

Analysis of MR images

MR images were read in consensus by two of the authors (P.C., C.P.) at a workstation with the Impax 6 Agfa Healthcare picture archiving and communication system (PACS). The 
compartments housing the ankle tendons were divided into three: the posterior compartment containing the $\mathrm{ACH}$ tendon; the lateral compartment containing the PL and PB tendons; and the medial compartment with the tibialis posterior (TP), flexor digitorum longus (FDL), and flexor hallux longus (FHL) tendons (Fig. 1). The transverse (T) and anteroposterior (AP) diameters of these six tendons were measured and the sectional area was calculated. For the ACH tendon only, the AP and T diameters, measured at its thickest segment, were taken into consideration as available published data have indicated that the area of the tendon is not critical for the diagnosis of tendinosis [15-17]. The peroneal tendons were measured $15 \mathrm{~mm}$ above the fibular tip, corresponding to the proximal segment of the peroneal tunnel, where they are kept in place by the superior peroneal retinaculum (Fig. 2) [4]. The medial flexor tendons were measured $6 \mathrm{~mm}$ below the level of the talar dome to include the segment of the flexor tendons enclosed by the flexor retinaculum (Fig. 3) [4]. The presence of tendon abnormality including tendinosis, tenosynovitis (not applicable to the $\mathrm{ACH}$ tendon), low- and high-grade partial tear, and complete tear involving the ACH, PL, PB, TP, FDL, and FHL tendons was registered after evaluation of the full length of the tendon. Tendinosis was defined as irregularity of the tendon contour and/or intrasubstance intermediate signal in fluid-sensitive sequences, and tenosynovitis was defined as the presence of circumferential fluid within the synovial tendon sheath greater than $3 \mathrm{~mm}$ in maximal width [18]. For the ACH, tendinosis was also considered present if the tendon's AP diameter was greater than $0.7 \mathrm{~cm}$, and paratenonitis if there was a halo of high signal about the tendon in fluid-sensitive sequences $[16,19,20]$. For the other ankle tendons (peroneal tendons and medial flexor tendons), as there is no consensus in the literature defining a cut-off diameter for the diagnosis of tendinosis, the only criterion that was used to define tendinosis was the presence of the qualitative features previously noted. Low-grade partial tear was defined as an intrasubstance area of high signal in fluid-sensitive sequences, with or without extension to the tendon surface. High-grade partial tear and complete tear were defined as near full thickness or full thickness discontinuity of the tendon fibers, respectively.
Statistical analysis

The relationship between tendon dimensions from the three different ankle compartments (lateral, medial, and posterior) as well as between tendons from the same compartment was analyzed using Pearson's correlation and the ANOVA tests. These dimensions were also correlated with age, gender, laterality, and weight of each patient also using Pearson's correlation and the ANOVA tests. The strength of the correlation was quantified according to the $r$ value, and a $p$ value $<0.05$ was considered as a statistically significant difference.

The association between the presence of qualitative abnormality among the several tendons was analyzed using the Chi-square test $\left(\chi^{2}\right)$, and a $p$ value $<0.05$ was considered as statistically significant. The association between the presence of qualitative abnormality in the $\mathrm{ACH}$ and the diameters and sectional area of the other ankle tendons was analyzed using the $t$ test, and a $p$ value $<0.05$ was considered as statistically significant.

\section{Results}

Quantitative results

The values for the mean, 10th, 50th (median) and 90th percentiles, ranges and standard deviation of the diameters, and areas of all the studied tendons are shown in Table 1.

Results of statistical analysis (Pearson's correlation and ANOVA) (Tables 2, 3, 4, and 5) for the relationship between the diameters of the ankle tendons revealed a statistically significant correlation between all the tendons in at least one of the diameters and/or areas, except for the PB tendon. No correlation could be found between the dimensions of the $\mathrm{PB}$ tendon and any of the other tendons dimensions $(p>0.05)$.

Intracompartmental analysis between the dimensions of the two peroneal tendons showed a positive correlation between at least one of the diameters and/or areas of both tendons $(p<0.018)$. The same was also demonstrated among

Table 4 Relationship between the dimensions of the peroneal tendons

\begin{tabular}{|c|c|c|c|c|c|c|c|}
\hline & \multirow[t]{3}{*}{ Diameter/area } & \multicolumn{6}{|c|}{ Peroneus brevis tendon } \\
\hline & & \multicolumn{2}{|c|}{ Transverse } & \multicolumn{2}{|c|}{ Anteroposterior } & \multicolumn{2}{|l|}{ Area } \\
\hline & & $p$ value $^{\mathrm{a}}$ & $r$ value $\mathrm{e}^{\mathrm{b}}$ & $p$ value $^{\mathrm{a}}$ & $r$ value ${ }^{\mathrm{b}}$ & $p$ value $^{\mathrm{a}}$ & $r$ value $^{\mathrm{b}}$ \\
\hline \multirow[t]{3}{*}{ Peroneus longus tendon } & Transverse & $<0.001$ & 0.396 & 0.702 & 0.039 & 0.018 & 0.237 \\
\hline & Anteroposterior & 0.017 & -0.238 & $<0.001$ & 0.342 & 0.111 & 0.160 \\
\hline & Area & 0.524 & 0.064 & 0.005 & 0.280 & 0.005 & 0.277 \\
\hline
\end{tabular}

\footnotetext{
${ }^{\text {a }}$ Calculated with ANOVA test

${ }^{\mathrm{b}}$ Calculated with Pearson correlation test
} 


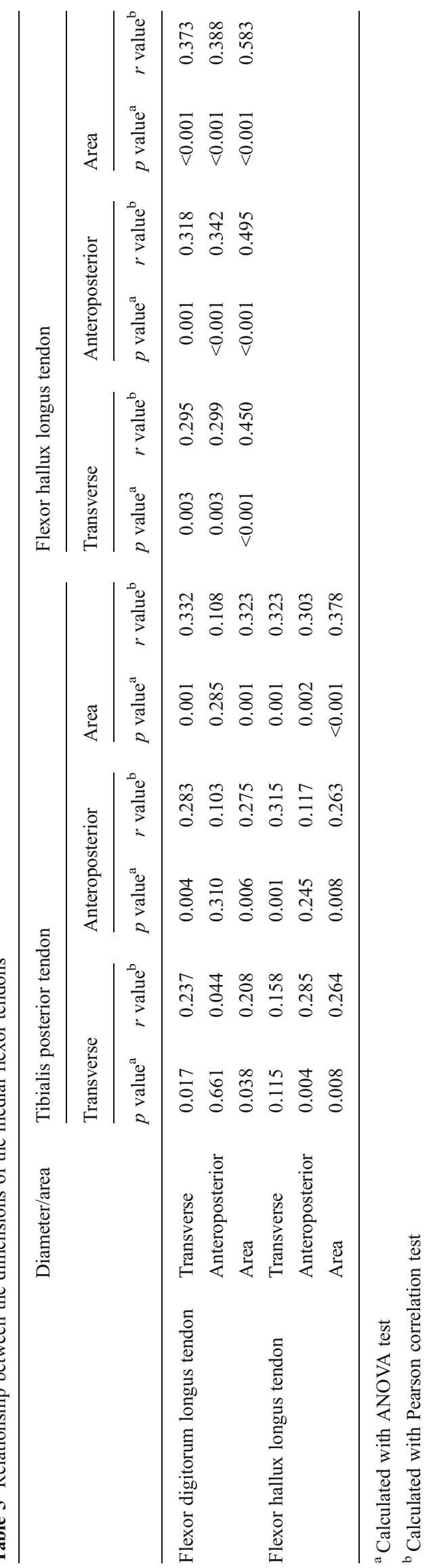

the three flexor tendons. The diameters and area of the FDL and FHL tendons correlated positively $(p<0.003)$. The TP tendon diameters and area correlated with the FDL tendon dimensions $(p=0.038)$ except for the AP diameter of the FDL tendon that did not correlate with any of the TP tendon diameters or area $(p>0.05)$. The same was evident for the TP and FHL tendons $(p=0.008)$. Only the transverse and AP diameters of the TP and FHL tendons did not show a correlation $(p>0.05)$.

A significant association was identified between patients' age and $\mathrm{ACH}$ tendon $\mathrm{T}$ and $\mathrm{AP}$ diameters with older patients having thicker $\mathrm{ACH}$ tendons $(p=0.002$ and $r=0.300$ for $\mathrm{T}$ diameter and $p=0.002$ and $r=0.302$ for AP diameter). Age also correlated positively with the FHL tendon dimensions, but no association was present between patients' age and the PB, TP, and FDL tendons dimensions (Table 6). Gender also showed significant correlation, with men having larger $\mathrm{ACH}$ tendon diameters, TP tendon AP diameter, and FDL and FHL tendons diameters and areas, compared to women $(p<$ $0.05)$ (Table 6). The weight of the patients and the specific side (i.e., right or left) were both statistically independent of all of the tendons' dimensions $(p>0.05)$ (Table 6).

Qualitative results

In $17(17 \%)$ of the MR imaging examinations, an abnormality concerning one of the medial compartment flexor tendons was found. In this group, 14 patients $(82 \%)$ had abnormality both to one of the medial flexor tendons and at least to one of the peroneal tendons. There was an association between MR imaging evidence of medial compartment flexor tendon abnormality and peroneal tendon abnormality $(p=0.032)$ (Table 7).

Forty-eight (48\%) of all the patients examined had tendinosis, tenosynovitis, or a tear of the PB tendon, and $35(35 \%)$ had an abnormality in the PL tendon. The incidence of a simultaneous abnormality in both of the peroneal tendons was $24 \%(24 / 100 ; p=0.002)$ (Table 7$)$.

Forty-four patients (44\%) had abnormalities of the ACH tendon in the form of paratenonitis, tendinosis, or tear. In twenty seven (61\%) of these cases, there was a concomitant abnormality of one of the peroneal tendons, in ten cases (23\%) of one of the medial flexor tendons, and in eight cases $(18 \%)$ of at least one of the peroneal tendons and at least one of the medial flexor tendons $(p>0.05)$ (Table 7).

The mean diameters and areas of the PL, TP, FDL, and FHL tendons were significantly higher in the group of subjects with ACH tendon abnormality (paratenonitis, tendinosis, or rupture) than in the group with a normal ACH tendon $(p<0.05)$. The difference of the means for the PB tendon diameters and area was not statistically significant $(p>0.05)$ (Table 8). 
Table 6 Relationship between tendons diameters/area and age, gender, side and weight

\begin{tabular}{|c|c|c|c|c|c|c|c|c|c|}
\hline \multirow[t]{2}{*}{ Tendons } & \multirow[t]{2}{*}{ Diameter/area } & \multicolumn{2}{|l|}{ Age } & \multicolumn{2}{|l|}{ Gender } & \multicolumn{2}{|l|}{ Side } & \multicolumn{2}{|l|}{ Weight $^{\mathrm{a}}$} \\
\hline & & $p$ value $^{\mathrm{b}}$ & $r$ value $^{\mathrm{c}}$ & $p$ value $^{\mathrm{b}}$ & $r$ value $^{\mathrm{c}}$ & $p$ value $^{\mathrm{b}}$ & $r$ value ${ }^{\mathrm{c}}$ & $p$ value $^{\mathrm{b}}$ & $r$ value \\
\hline \multirow[t]{2}{*}{ Achilles } & Transverse & 0,002 & 0.309 & 0.005 & 0.281 & 0.119 & -0.134 & 0.725 & 0.036 \\
\hline & Anteroposterior & 0,002 & 0.300 & 0.297 & 0.105 & 0.213 & -0.126 & 0.434 & 0.079 \\
\hline \multirow[t]{3}{*}{ Peroneus longus } & Transverse & 0,504 & 0.068 & 0.960 & 0.167 & 0.878 & -0.016 & 0.391 & 0.087 \\
\hline & Anteroposterior & 0,640 & 0.047 & 0.540 & 0.193 & 0.499 & -0.068 & 0.497 & 0.069 \\
\hline & Area & 0,485 & 0.071 & 0.006 & 0.275 & 0.637 & -0.048 & 0.253 & 0.115 \\
\hline \multirow[t]{3}{*}{ Peroneus brevis } & Transverse & 0,143 & 0.148 & 0.534 & 0.063 & 0.215 & -0.125 & 0.100 & 0.166 \\
\hline & Anteroposterior & 0,419 & 0.082 & 0.788 & 0.027 & 0.383 & 0.088 & 0.698 & 0.039 \\
\hline & Area & 0,164 & 0.140 & 0.671 & 0.043 & 0.977 & -0.003 & 0.257 & 0.114 \\
\hline \multirow[t]{3}{*}{ Tibialis posterior } & Transverse & 0,249 & 0.114 & 0.619 & -0.500 & 0.174 & 0.137 & 0.131 & 0.152 \\
\hline & Anteroposterior & 0,724 & 0.036 & $<0.001$ & 0.448 & 0.212 & -0.126 & 0.780 & 0.028 \\
\hline & Area & 0,255 & 0.115 & 0.015 & 0.242 & 0.945 & 0.007 & 0.273 & 0.111 \\
\hline \multirow[t]{3}{*}{ Flexor digitorum longus } & Transverse & 0,536 & 0.063 & 0.021 & 0.231 & 0.602 & -0.059 & 0.910 & 0.011 \\
\hline & Anteroposterior & 0,435 & 0.079 & 0.007 & 0.27 & 0.356 & 0.093 & 0.155 & 0.143 \\
\hline & Area & 0,193 & 0.131 & $<0.001$ & 0.348 & 0.121 & -0.156 & 0.707 & 0.038 \\
\hline \multirow[t]{3}{*}{ Flexor hallux longus } & Transverse & 0,009 & 0.260 & $<0.001$ & 0.396 & 0.063 & -0.186 & 0.306 & 0.103 \\
\hline & Anteroposterior & $<0.001$ & 0.379 & 0.458 & 0.075 & 0.326 & -0.099 & 0.541 & 0.062 \\
\hline & Area & $<0.001$ & 0.380 & 0.005 & 0.281 & 0.098 & -0.167 & 0.452 & 0.076 \\
\hline
\end{tabular}

${ }^{a}$ Data on weight was available only from 68 patients

${ }^{\mathrm{b}}$ Calculated with ANOVA test

${ }^{\mathrm{c}}$ Calculated with Pearson correlation test

\section{Discussion}

Our results indicate that there is a positive correlation between the AP diameter of the ACH tendon (indicative of tendinosis) and the diameters and area of the PL tendon and the three medial compartment tendons (TP, FDL, and FHL tendons). Subjects with a larger AP diameter of the ACH tendon revealed PL, TP, FDL, and FHL tendons with larger diameters and sectional areas. Furthermore, the medial ankle tendons and the PL tendon also had a positive correlation with regard to their diameters and areas, with few exceptions in some of the measurements. This positive correlation was also found when the medial compartment tendons were individually assessed and compared to each other.

Based on our data, there seems to exist a link between the sectional size of the various ankle tendons. Therefore, a subtle abnormality of one of the tendons, reflected by an increase in its diameter, is very frequently accompanied by similar changes in tendons both in the same compartment and in the other two ankle compartments. This was shown in our study for all tendons except for the PB tendon. The fact that none of the measurements related to the PB tendon correlated with any of the other tendons' dimensions ( $p>$ 0.05 ) may be explained by the variability of its sectional shape, which makes it difficult to define its exact diameters and area. The frequent finding of a split-type tear without tendinosis-related diameter increase, instead of the more typical diameter increase that occurs in tendinosis of the other ankle tendons, could also be an explanation since this split-type tear of the PB usually decreases the tendon diameter and area.

Several observations and potential limitations in this study should be emphasized. Based on available literature, the $\mathrm{ACH}$ tendon size seems to be directly related to lean body mass and total body mass and, further, women seem to have slightly thinner ankle tendons than men, but the difference has not been found to be statistically significant $[21,22]$. We could not find any studies correlating height, weight, or body mass index of persons with the cross-sectional diameters of the peroneal tendons or the medial flexor tendons. Nevertheless, to avoid this possible bias, the age, gender, and weight of the subjects and laterality of the ankle being studied were also analyzed with the purpose of trying to establish the statistical independence of these variables. Data regarding weight could be retrieved for 68 of the subjects. The statistical analysis did not show any relationship between the weight of the subjects and the diameter of the tendons, which makes it less likely that the correlations found between the tendon diameters could be the result of weight bias. Since only the ACH and the FHL tendons showed a positive correlation with the age of the patient, the presence of bias due to this relationship is also very unlikely. 
Table 7 Relationship between the incidence of injury in ankle tendons

\begin{tabular}{clccc}
\hline \multirow{2}{*}{ Medial flexors $x$ Peroneals } & & \multicolumn{2}{c}{ Peroneals } & \\
\cline { 3 - 4 } & & Normal & Injury & TOTALS \\
\cline { 3 - 4 } & Normal & 38 & 45 & 83 \\
\multirow{2}{*}{ Medial flexors } & Injury & 3 & 14 & 17 \\
& TOTALS & 41 & 59 & 100 \\
\hline P $-0.032^{*}$ & & &
\end{tabular}

\begin{tabular}{clccc}
\multirow{2}{*}{ Peroneus longus $x$ Peroneus brevis } & \multicolumn{2}{c}{ Peroneus brevis } & \\
\cline { 3 - 4 } & & Normal & Injury & TOTALS \\
\hline \multirow{2}{*}{ Peroneus longus } & Normal & 41 & 24 & 65 \\
& Injury & 11 & 24 & 35 \\
& TOTALS & 52 & 48 & 100 \\
\hline
\end{tabular}

$P-0.002^{*}$

Achilles $x$ Peroneals

Peroneals

\begin{tabular}{clccc} 
& & Normal & Injury & TOTALS \\
\hline \multirow{3}{*}{ Achilles } & Normal & 24 & 32 & 56 \\
& Injury & 17 & 27 & 44 \\
& TOTALS & 41 & 59 & 100 \\
\hline
\end{tabular}

$P-0.670^{*}$

\begin{tabular}{clccc} 
Achilles $x$ Medial flexors & & \multicolumn{2}{c}{ Medial flexors } & \\
\cline { 3 - 4 } & & Normal & Injury & TOTALS \\
\hline \multirow{2}{*}{ Achilles } & Normal & 49 & 7 & 56 \\
& Injury & 34 & 10 & 44 \\
& TOTALS & 83 & 17 & 100 \\
\hline
\end{tabular}

$P-0.177^{\star}$

*Calculated with Chi-square tests

Male gender correlated positively with the tendons' dimensions but, given that our sample was almost evenly divided with 52 females and 48 male subjects, a meaningful influence of this factor on our conclusions is also very unlikely.

The position of the foot, namely, the degree of flexion or extension, at the ankle, could eventually influence the tendons' diameters, though no controlled studies have been conducted on the subject. By using five different MR units and different water-sensitive sequences, some minor degree of measurement variation is also expected, but also on this subject no conclusive data has been published.

To reduce even more the measurement related bias just indicated (due to age, gender, weight, laterality, and ankle position), we attempted to define a direct association only of the presence of qualitative abnormalities in the different tendons and a statistically significant association was found between the medial flexor and the peroneal tendons and also between the PB and PL tendons, meaning that subjects with tendinosis with altered signal and contour irregularity or with tendon tear in one of the medial tendons had a higher likelihood of showing tendinosis or tearing in one of the peroneal tendons, with the opposite also true. Although a statistically significant association could not be shown between the presence of abnormalities in the $\mathrm{ACH}$ tendon and in the other tendons based exclusively on qualitative assessment, a clear trend was present, with a higher frequency of abnormalities in the peroneal and medial tendons in subjects with $\mathrm{ACH}$ paratenonitis, tendinosis or tendon tears. A significant statistical association was in fact shown but only when the presence of $\mathrm{ACH}$ tendon qualitative abnormalities was correlated to the diameters and areas of all of the ankle 
Table 8 Relationship between injury of the Achilles tendon and the dimensions of the other tendons

\begin{tabular}{|c|c|c|c|c|}
\hline Tendon measurement $(\mathrm{cm})$ & & $\begin{array}{l}\text { Achilles tendon } \\
\text { with injury }^{\mathrm{a}}\end{array}$ & $\begin{array}{l}\text { Achilles tendon } \\
\text { without injury }\end{array}$ & $p^{\mathrm{b}}$ \\
\hline \multirow[t]{3}{*}{ Peroneus longus } & Transverse & 0.707 & 0.644 & $<0.05$ \\
\hline & Anteroposterior & 0.443 & 0.389 & $<0.05$ \\
\hline & Area & 0.246 & 0.193 & $<0.01$ \\
\hline \multirow[t]{3}{*}{ Peroneus brevis } & Transverse & 0.663 & 0.631 & $>0.05$ \\
\hline & Anteroposterior & 0.329 & 0.274 & $>0.05$ \\
\hline & Area & 0.163 & 0.128 & $>0.05$ \\
\hline \multirow[t]{3}{*}{ Tibialis posterior } & Transverse & 0.526 & 0.453 & $<0.01$ \\
\hline & Anteroposterior & 1.089 & 1.005 & $<0.05$ \\
\hline & Area & 0.449 & 0.356 & $<0.01$ \\
\hline \multirow[t]{3}{*}{ Flexor digitorum longus } & Transverse & 0.538 & 0.453 & $<0.01$ \\
\hline & Anteroposterior & 0.438 & 0.382 & $<0.05$ \\
\hline & Area & 0.176 & 0.133 & $<0.01$ \\
\hline \multirow[t]{3}{*}{ Flexor hallux longus } & Transverse & 0.590 & 0.501 & $<0.01$ \\
\hline & Anteroposterior & 0.423 & 0.348 & $<0.01$ \\
\hline & Area & 0.197 & 0.139 & $<0.01$ \\
\hline
\end{tabular}

${ }^{\text {a }}$ Presence of criteria for paratenonitis, tendinosis, or tearing in MR imaging

${ }^{\mathrm{b}}$ Significance calculated with $t$ test

tendons (once again with the exception of the PB tendon). Subjects with a qualitatively abnormal $\mathrm{ACH}$ tendon revealed PL, TP, FDL, and FHL tendons that had larger AP and $\mathrm{T}$ diameters and larger sectional areas than subjects with normal $\mathrm{ACH}$ tendons. This strongly supports the idea that there is a link between abnormality in the ACH tendon and in all of the other ankle tendons.

With regard to the explanation of this link, a possible role of the retinacula in maintaining the structural equilibrium between the three ankle compartments should be considered. Indeed, a complex relationship between the retinacula and adjacent tendons may hold the key to tendon function and integrity and explain the association of abnormalities of the various tendon groups. Nevertheless, several confounding factors cannot be ignored and can be responsible for the present results. Some were already addressed, and others inherent to the study protocol like patient selection and image reading and measuring biases as well as the limited number of the sample can limit the extent of our conclusions.

\section{Conclusions}

A statistical correlation was found between the diameters and sectional areas of most of the ankle tendons as well as between qualitative abnormalities on MR images of these tendons. This association seems to indicate that abnormalities in one of the tendons may influence the integrity of the other tendons perhaps on the basis of a retinacular and fascial system that connects them. Future research in this area should be pursued with larger samples and focusing on tendon and retinacular relationship.

Disclosure The authors declare that they have no conflicts of interest.

Open Access This article is distributed under the terms of the Creative Commons Attribution License which permits any use, distribution, and reproduction in any medium, provided the original author(s) and the source are credited.

\section{References}

1. Sarrafian SK. Anatomy of the foot and ankle: descriptive, topographic, functional. 2nd ed. Philadelphia: Lippincott Williams \& Wilkins; 1993. p. 113-58.

2. Carmont MR, Highland AM, Rochester JR, Paling EM, Davies MB. An anatomical and radiological study of fascia cruris and paratenon of the Achilles tendon. Foot Ankle Surg. 2011;17(3):186-92.

3. Stecco C, Macchi V, Porzionato A, et al. The ankle retinacula: morphological evidence of the proprioceptive role of the fascial system. Cells Tissues Organs. 2010;192(3):200-10.

4. Numkarunarunrote N, Malik A, Aguiar RO, Trudell DJ, Resnick D. Retinacula of the foot and ankle: MRI with anatomic correlation in cadavers. AJR Am J Roentgenol. 2007;188(4):W348-54.

5. Lee J, Schuberth JM. Concomitant rupture of Achilles tendon and superior peroneal retinaculum: a case report. J Foot Ankle Surg. 2010;49(2):176-8.

6. Marti RK, van der Werken C, Schütte PR, Bast TJ. Operative repair of ruptured Achilles tendon and functional aftertreatment-I. Acute rupture. Neth J Surg. 1983;35(2):61-4. 
7. Stecco A, Stecco C, Macchi V, et al. RMI study and clinical correlations of ankle retinacula damage and outcomes of ankle sprain. Surg Radiol Anat. 2011;33(10):881-90.

8. Gheno R, Nico MA, Buck FM, Trudell DJ, Haghighi P, Resnick D. Edematous processes within Kager fat pad: magnetic resonance imaging, gross anatomical, and histological studies in cadavers with clinical correlation. J Comput Assist Tomogr. 2010;34(4):621-5.

9. Villarreal AD, Andersen CR, Panchbhavi VK. A survey on management of chronic Achilles tendon ruptures. Am J Orthop (Belle Mead NJ). 2012;41(3):126-31.

10. Gluck GS, Heckman DS, Parekh SG. Tendon disorders of the foot and ankle, part 3: the posterior tibial tendon. Am J Sports Med. 2010;38(10):2133-44.

11. Ziai P, Benca E, von Skrbensky G, et al. The role of the peroneal tendons in passive stabilisation of the ankle joint: an in vitro study. Knee Surg Sports Traumatol Arthrosc. 2012. doi:10.1007/s00167012-2273-2.

12. Demondion X, Canella C, Moraux A, Cohen M, Bry R, Cotten A. Retinacular disorders of the ankle and foot. Semin Musculoskelet Radiol. 2010;14(3):281-91.

13. Heckman DS, Gluck GS, Parekh SG. Tendon disorders of the foot and ankle part 1: peroneal tendon disorders. Am J Sports Med. 2009;37(3):614-25.
14. Weseley MS, Koval R, Kleiger B. Roentgen measurement of ankle flexion-extension motion. Clin Orthop Relat Res. 1969;65:167-74.

15. Harris CA, Peduto AJ. Achilles tendon imaging. Australas Radiol. 2006;50:513-25.

16. Pierre-Jerome C, Moncayo V, Terk MR. MRI of the Achilles tendon: a comprehensive review of the anatomy, biomechanics and imaging of overuse tendinopathies. Acta Radiol. 2010;51(4):438-54.

17. Heckman DS, Gluck GS, Parekh SG. Tendon disorders of the foot and ankle part 2: Achilles tendon disorders. Am J Sports Med. 2009;37(6):1223-34.

18. Kijowski R, De Smet A, Mukharjee R. Magnetic resonance imaging findings in patients with peroneal tendinopathy and peroneal tenosynovitis. Skeletal Radiol. 2007;36(2):105-14.

19. Soila K, Karjalainen PT, Aronen HJ, Pihlajamäki HK, Tirman P. High-resolution MR imaging of asymptomatic Achilles tendon: new observations. AJR Am J Roentgenol. 1999;173(2):323-8.

20. Karjalainen PT, Soila K, Aronen HJ, et al. MR imaging of overuse injuries of the Achilles tendon. AJR Am J Roentgenol. 2000;175(1):251-60.

21. Schweitzer ME, Karasick D. MR imaging of disorders of the Achilles tendon. AJR Am J Roentgenol. 2000;175(3):613-25.

22. Koivunen-Niemelä T, Parkkola K. Anatomy of the Achilles tendon (tendo calcaneus) with respect to tendon thickness measurements. Surg Radiol Anat. 1995;17(3):263-8. 